\title{
3D-printed rapid prototype rigs for surface mounted PM rotor controlled segment magnetisation and assembly
}

DOI:

10.1109/IEMDC.2019.8785121

\section{Document Version}

Accepted author manuscript

Link to publication record in Manchester Research Explorer

\section{Citation for published version (APA):}

Durovic, S., Mohammed, A., \& Melecio Ramirez, J. (2019). 3D-printed rapid prototype rigs for surface mounted PM rotor controlled segment magnetisation and assembly. In IEEE International Conference on Electric Machines and Drives IEMDC 2019 (pp. 1-7). IEEE. https://doi.org/10.1109/IEMDC.2019.8785121

\section{Published in:}

IEEE International Conference on Electric Machines and Drives IEMDC 2019

\section{Citing this paper}

Please note that where the full-text provided on Manchester Research Explorer is the Author Accepted Manuscript or Proof version this may differ from the final Published version. If citing, it is advised that you check and use the publisher's definitive version.

\section{General rights}

Copyright and moral rights for the publications made accessible in the Research Explorer are retained by the authors and/or other copyright owners and it is a condition of accessing publications that users recognise and abide by the legal requirements associated with these rights.

\section{Takedown policy}

If you believe that this document breaches copyright please refer to the University of Manchester's Takedown Procedures [http://man.ac.uk/04Y6Bo] or contact uml.scholarlycommunications@manchester.ac.uk providing relevant details, so we can investigate your claim.

\section{OPEN ACCESS}




\title{
3D-printed rapid prototype rigs for surface mounted PM rotor controlled segment magnetisation and assembly
}

\author{
Juan I. Melecio*, A. Mohammed", Nigel Schofield ${ }^{\dagger}$ and S. Djurović* \\ School of Electrical and Electronic Engineering \\ ${ }^{*}$ University of Manchester, Manchester, ${ }^{\dagger}$ University of Huddersfield, Huddersfield, UK \\ Ignacio.Melecio@manchester.ac.uk,Sinisa.Durovic@manchester.ac.uk
}

\begin{abstract}
This paper examines the feasibility of dedicated 3-D printed rigs use for enabling effective build and magnetisation of $P M$ segments and controlled $P M$ rotor assembly of a surface mounted PM rotor design. To this end a commercial surface mounted PM rotor design has been rebuilt and modified to allow for representation of a range of different PM magnetisation conditions. It is shown that suitable geometry assembly rigs made of electrically and magnetically passive material can be rapidly prototyped using 3D printing and applied to enable efficient PM segment build and magnetisation in a desired layout, as well as controlled surface mounted PM rotor assembly.
\end{abstract}

Keywords- Permanent Magnet Synchronous Machine, rapid prototyping, demagnetisation, PM arc build, PM rotor assembly, fault analysis

\section{INTRODUCTION}

Permanent Magnet Synchronous Machines (PMSM) are key elements of a number of vital contemporary industrial systems, ranging from transportation to military, medical, factory automation, aerospace, wind energy systems and other applications [1], [2]. A leading example of growing PMSM applications is the electric vehicle (EV) and hybrid electric vehicle (HEVs) market, where the PMSM is the currently favoured choice of propulsion machine design due to relatively high efficiency, high output power to volume ratio, and high torque to current ratio [1], [3], [4]. The high performance of PMSMs is primarily enabled by effective permanent magnet $(\mathrm{PM})$ rotor design, whether in surface mounted (SPM) or interior (IPM) form. Both forms require controlled magnetisation and assembly of specially shaped magnet segments.

In SPM designs, which are in the focus of this study, PM elements are installed on the rotor core surface with a requirement for a mechanical retention band or sleeve to ensure PM positional integrity to rotation induced centrifugal forces. Conventional practice in SPM build generally dictates that PM segments are pre-magnetised in a particular geometry to then be installed on the rotor. This requires the manufacture of PM segments in desired geometry and purpose built rigs to enable their appropriate positioning and protection during the magnetisation process. Furthermore, the assembly process of pre-magnetised PMs into the final SPM rotor design can require specialised fixtures to handle PM elements with appropriate care and locate them precisely on the rotor, preventing them from being damaged in the process and ensuring personnel safety from potentially strong attractive or repulsive magnetic forces. Despite PMSMs being widely used today, the PM rotor production processes are still largely manually driven due to different rotor sizes, complexities and motor designs [5].

The commercial process of creating the fixture concepts required to handle PMs generally includes computer aided design (CAD), taking into consideration specific requirements for positioning and insertion of PMs and their alignment over the rotor [6]. Once finalised, conceptual fixture design is typically followed by CAD fixture model reproduction with the aid of advanced machining tools (i.e., computer numerical control -CNC- machining) [7]. The overall process can be of non-trivial complexity with a not insignificant amount of time needed from conception to creation of a prototype and with requirements for use of advanced tools. There is a general interest in enabling a more straightforward methodology that facilitates desired PM form magnetisation and rapid and effective build of SPM rotors; this is especially pertinent in the academic sector where access to advanced tooling capabilities is generally limited, yet a considerable interest in analysis of PM rotor effects exists, ranging from design to demagnetisation related phenomena [8], [9], [10], [11], [12], [13].

Rapid Prototyping (RP) is an additive fabrication technology which can create complex 3-dimensional (3D) prototypes in a short period of time; it uses a 3D CAD geometry model which is cut in fine $2 \mathrm{D}$ slices or layers that are transferred to a machine that reproduces each layer to recreate the desired geometry [14]. The latest generation of RP technologies, such as Fused Deposition Modelling (FDM), Stereolithography (SLA) or Selective Laser Melting (SLM), enable creation of a prototype within hours [11]. In comparison with subtractive technologies (e.g. CNC machining), there is less wasted material with $3 \mathrm{D}$ printing: no scrap, milling or sanding, with an added benefit that $95 \%$ $98 \%$ of waste material can be recycled [16]. Additionally, the use of additive fabrication technology to create rapid prototypes could optimise energy consumption by utilising only the amount of material needed for a prototype, which is key to environmental sustainability [17]. RP is increasingly finding implementation in a number of sectors, such as automotive, medical, electrical and aerospace, with reported use of materials such as polymers or metallic alloy powders [18], [19].

This paper investigates the feasibility of purpose designed 3D printed rapid prototype rigs use for SPM rotor segment controlled magnetisation and assembly process in a low powered PMSM. The reported work underpins a larger study aimed at analysis of demagnetisation effects in SPM machines. A commercial six pole SPM rotor design utilising grade ND-35 Neodymium PMs has been disassembled and 
individual PM arcs redesigned to allow axial and circumferential segmentation in each pole with a view to enabling controlled introduction of a desired level and form of demagnetisation. Two purpose designed 3D rig architectures are then proposed: the PM arc assembly rig enables segmented PM arc assembly in a configuration allowing the introduction of a range of magnetisation levels and forms during the magnetisation process and build of fully or partly magnetised segmented PM arcs, while the SPM rotor assembly cage rig facilitates effective assembly of partly or fully magnetised PM arcs on the rotor. The proposed rigs utilise electrically and magnetically passive material and thus eliminate the electrical or thermal hazards associated with the magnetisation process; the assembly rig is designed to enable efficient retention of PM material volume during magnetisation, thus minimising the risk of PM mechanical damage due to magnetisation imposed stress.

The designed prototypes were produced using a commercial 3D RP machine. The performance and effectiveness of the produced assembly rigs was first assessed through their use for build and magnetisation of segmented PM arcs for a practical SPM design; the produced arcs were then assembled on the PM rotor core using the produced rotor assembly cage rigs. Two SPM rotor prototypes were built using this methodology and practically tested: one fully magnetised and the other emulating uniform demagnetisation effects.

\section{PROTOTYPE DESIGN PROCESS}

Conventional PM rotor assembly process favours relatively complicated assembly rig designs typically requiring non-magnetic alloys used for building tooling and handling fixtures [5]. This study explores an alternative method for facilitating ease of prototype production for research purposes, in an attempt to address the lack of literature on PM rotor build for controlled emulation for demagnetisation states. To this end, this section presents a general description of the differences between rapid prototyping design process approach and the conventional approach generally used for prototype manufacturing.

A conventional prototype design process is depicted in Fig. 1. In general, the process commences with the design phase, which involves the translation of the prototype concept idea into a 3D or 2D CAD model. This could involve the development of an assembly which requires creation of multiple parts that could be produced by different conventional subtractive fabrication technologies [20]. The next step is the part creation phase, where the appropriate fabrication method and material are chosen. This stage also involves the conversion of the designed CAD model in a format ready to machine parts, commonly known as $\mathrm{CAD} / \mathrm{CAM}$ (computer aided manufacturing) process. The choice of proper tooling in this stage is critical for the precision and timing of the part design manufacture and is based on the complexity of its geometry and tolerances; to improve the final product surface roughness a final finishing process of the part might be performed. The final step is the verification phase, in which the functionality of the part in its particular application is tested, such as in an assembly with other parts. The entire process is iterative and if some of the outcomes of any phase are inadequate or do not satisfy the functional requirements, the process is repeated. In general, the conventional prototype design process is complex and the time for the creation of an assembly based on multiple parts could be long with a requirement for trained personnel for each of the machines involved in part production [20], [21].

To examine the feasibility of advancing this process for a particular electric motor part assembly and modification method, this paper explores the application of the RP design process, as illustrated in Fig. 2. Identical to the conventional process the RP process begins with a design phase as a first stage, in which the conceptual idea is generally transformed into a 3D CAD model. In this phase, a complex assembly could be designed, as the RP machine allows for a functional assembly to be fully printed at once, much reducing the time required for assembly of multiple parts [22]. Once, the 3D model is completed, the prototype creation phase starts. In this step, the 3D CAD model is converted into a RP printing format, commonly known as .STL (stereolithography) file in which the model is layered. This file is then transferred to the RP machine and the printer is configured by allocating the assembly or prototype parts in the printing bed (parts orientation). Depending on the application of the prototype and the RP printer technology, different build speeds can be achieved with different build materials options, such as engineering plastics as ABS, PLA, ASA, carbon fibre or metallic powder alloys [21], [22]. Once this step is finalised, the prototype is ready to be printed. The final step is the finishing of the part, which involves the removal of the support material either by chemical (i.e chemical water bath), hand or flush cutters. The final RP prototype design process step is the verification phase, in which the functionality of the prototype in its particular application is tested. This is also an iterative process where if any aspect of the desired outcome is inadequate the process is repeated until satisfactory product design is achieved.

This design process can enable creation of complex functional assemblies within a period of a few hours [21], [23]. In addition to part creation speed, the RP development process considerably improves the practical feasibility of small quantities production of parts or assemblies for laboratory research exploration, due to the flexibility it offers in concept design and modification process compared with subtractive technologies [24].

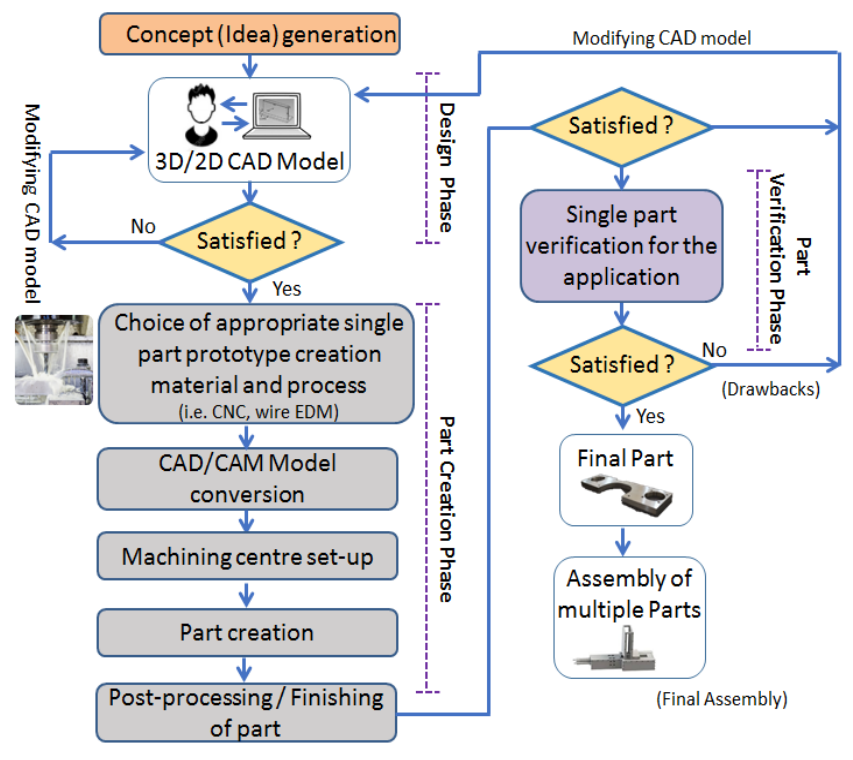

Fig. 1: Conventional prototype design process flow diagram 


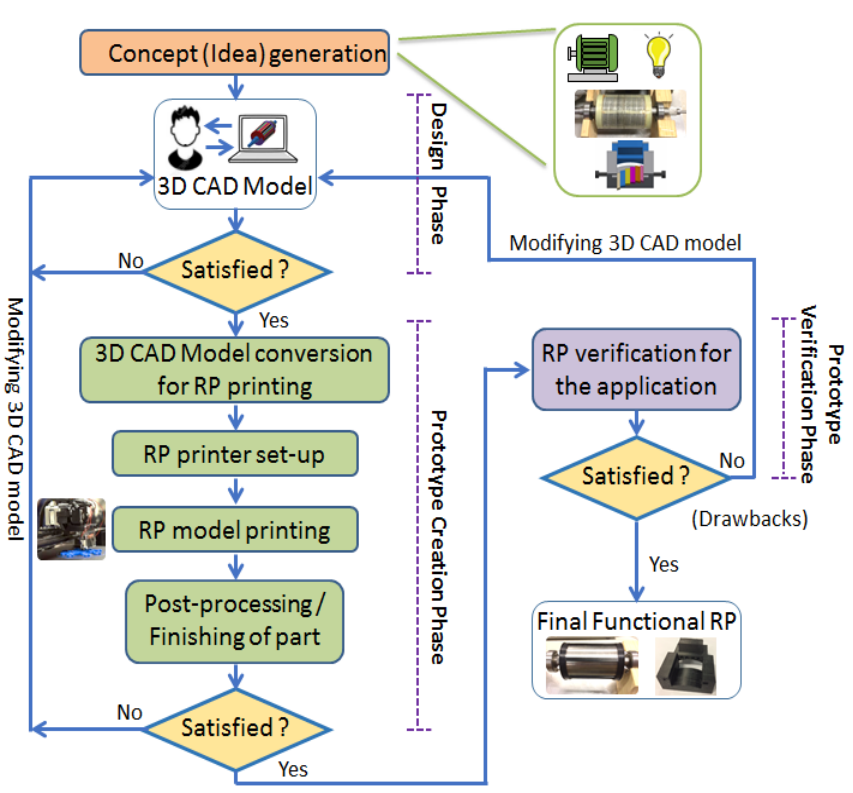

Fig. 2: RP design process flow diagram

\section{EXAMINED SPM ROTOR GEOMETRY}

This study examines a commercial $1.1 \mathrm{~kW}, 3$-phase, 415 $\mathrm{V}$, 6-pole PMSM with a non-skewed SPM rotor design containing arc-shaped PMs, with a pitch of $147^{\circ}\left(\propto_{e}\right)$, made of N-35 grade Neodymium, as shown in Fig. 3. To assist PM retention, two glass fibre covers were originally located in rotor ends during factory assembly process and a reinforced glass-fibre band applied over these and the PMs.

The original SPM assembly is modified in this study using the proposed $3 \mathrm{D}$ printed rigs to enable the construction of a rotor structure that allows for assessment of a range of distinct PM magnetisation conditions. The modified rotor assembly was created using the original shaft, bearings and core, however, to enable analysis of different magnetisation conditions in a controlled fashion, the original PM pole design was modified to be axially segmented into four aligned arc pieces, each of which is circumferentially segmented into six individual sections, as shown in Fig. 3.c. This facilitates controlled emulation of a range of typical conditions that can arise from different demagnetisation processes [9], [10] by appropriate magnetisation of individual PM sections and their careful assembly into complete PM poles to be installed on the rotor; the 3D printed PM and rotor assembly rig geometries detailed in this work have been designed to enable this process.

\section{PM ARC ASSEMBLY Rig}

The first phase in building the modified SPM rotor is to form individual arc sections that constitute PM poles when axially aligned. As detailed in section III, each arc section comprises of six separate PM segments which can be in different magnetisation states depending on the evaluated magnetisation conditions, and require precise and careful positioning to form the desired arc shape. To accomplish this, a PM arc segment assembly rig concept presented in

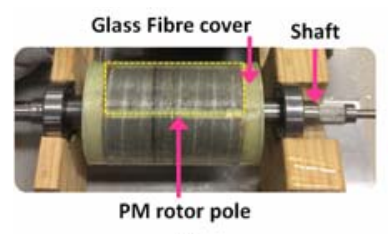

a)

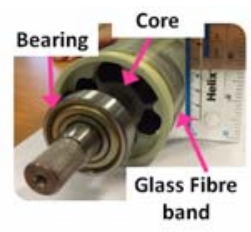

b)

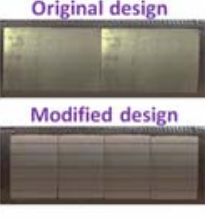

c)
Fig. 3: Commercial SPM rotor: a) top view, b) axial side view, c) PM rotor pole: original vs modified design

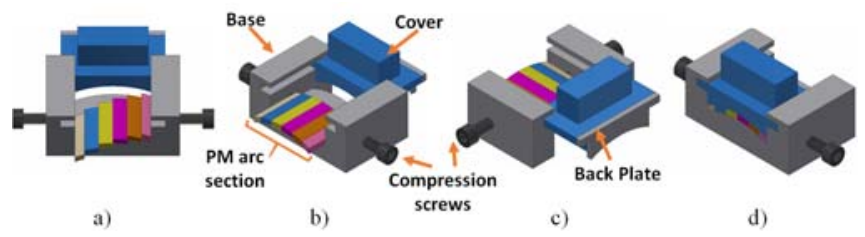

Fig. 4: PM arc assembly rig: a) General geometry, b) arc segment formation, c) cover and back plate location and d) complete arc segment assembly

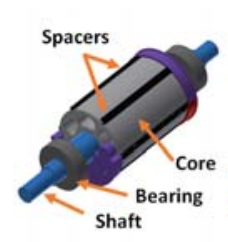

a)

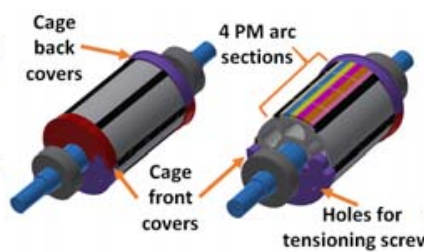

b) c)

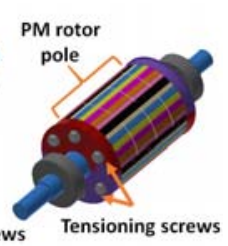

d)
Fig. 5: PM rotor assembly cage rig: a) spacer positions on the rotor surface, b) cage front and back covers, c) PM pole section assembly and d) complete rotor assembly

Fig. 4 was designed to enable the formation of PM arcs through bonding individual PM segments with adhesive in an arc formation whose curvature matches that of the rotor core outer circumference: the rig enables effective physical alignment of individual PM segments and their constriction until the adhesive dries and cures.

An important functional feature of the rig was the requirement for it to enable manipulation and bonding of magnetised and/or demagnetised PM segments. This was facilitated by the inclusion of a cover and two compression screws in the designed geometry to allow for containment and compression of the PM arcs, as needed in the assembly process. The assembly rig concept was developed using Inventor Professional by Autodesk $(\mathrm{C})$ which is a commercial 3D CAD modelling software.

The design of the assembly rig is conceived to employ a RP plastic material which has sufficient strength to withstand magnetic forces of magnetised PMs it houses, and equally importantly is not electrically or magnetically conductive, allowing its straightforward use for positioning, retention and protection of the built PM arcs during the magnetisation process.

\section{SPM Rotor Assembly CAGE DESIGN}

Once the individual PM arc sections are assembled using the rig system detailed in section IV, a SPM rotor assembly cage rig was designed to enable controlled installation of PMs on the rotor and its completion. To facilitate effective 
handling and location of PM arc segments, six spacers that fit the rotor surface area in which PMs are short pitched were designed; these effectively guide the insertion and positioning of individual pre-magnetised PM arcs and allow practical formation of complete PM poles. In order to axially constrain PM arcs belonging to individual poles and enable their straightforward axial alignment, a front and a back cage cover, each made up of interlocking 3D printed halves were designed following the features of the rotor geometry. Additionally, the covers include multiple holes to allow for insertion of tensioning axial screws that enable controlled force to be applied on PM material to position and retain it in appropriate locations. The proposed assembly cage design and its use are illustrated in Fig. 5.

\section{RESULTS}

\section{A. RP Machine used in the prototype creation}

The PM arc assembly rig and SPM rotor assembly cages were fabricated using a Dimension 1200es RP machine by Stratasys $($ ) which employs FDM technology with Stratasys $₫$ ABSplus-P430 thermoplastic material; the material thermal and mechanical properties are sufficient to withstand the assembly stresses of conventional low power PMSM machinery [25]. Fig. 6 shows the RP 3D models set-up in the software Dimension-CatalystEX from Stratasys $\subset$. The printing time of 4 PM arc assembly rigs and a complete SPM rotor assembly cage rig was $\approx 6$ hours with a resulting accuracy tolerance in produced geometries of $\approx 0.254 \mathrm{~mm}$. The specification of the RP Machine and material specifications are shown in Table I and Fig. 7.

\section{B. PM segmented rotor construction}

Once the RP components were printed, the PM arc assembly rigs were first used to assemble the individual PM segments into PM arc sections. This first part of the assembly process is described in Fig. 8 and illustrated in Fig. 9. A commercial high strength glue, Loctite $($ C48, was used for bonding separate segments. The RP arc assembly rig concept enables rapid and straightforward build of individual segments into the desired arc shape of appropriate geometry due to its design geometry that closely replicates the rotor core outer circumference curvature and the PM single pole axial segment dimensions.

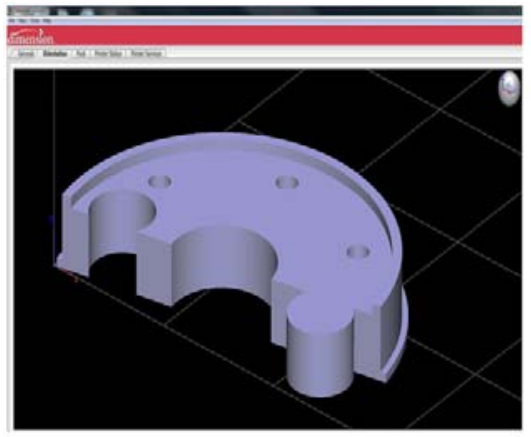

a)

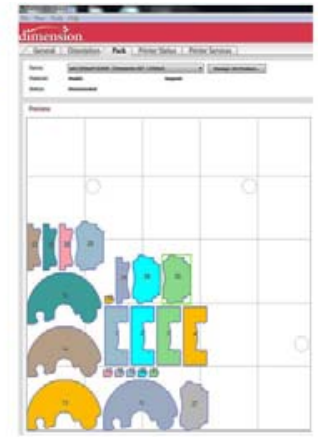

b)
Fig. 6: RP 3D geometry set-up: a) part orientation, b) complete parts for SPM rotor prototype assembly
TABLE I. RP MACHINE AND MATERIAL SPECIFICATIONS

\begin{tabular}{|c|c|}
\hline \multicolumn{2}{|c|}{ RP machine: Stratasys Dimension 1200es } \\
\hline Model Material & ABSplus \\
\hline Technology & Fused Deposition Modeling (FDM) \\
\hline Support Material & Soluble Support Technology (SST) \\
\hline Build size & $254 \times 254 \times 305 \mathrm{~mm}(10 \times 10 \times 12$ inches $)$ \\
\hline Thickness of layer & $0.254 \mathrm{~mm}(0.010 \mathrm{in})$ or $0.33 \mathrm{~mm}(0.013 \mathrm{in})$ \\
\hline Accuracy & $+/-.254 \mathrm{~mm}(+/-.01 \mathrm{in})$ \\
\hline \multicolumn{2}{|c|}{ RP machine material properties: ABSplus-P430 } \\
\hline $\begin{array}{c}\text { Heat Deflection (HDT), } \\
\text { @264 psi }\end{array}$ & $82^{\circ} \mathrm{C}\left(180^{\circ} \mathrm{F}\right)$ \\
\hline $\begin{array}{c}\text { Coefficient of Thermal } \\
\text { Expansion }\end{array}$ & $4.90 \times 10^{-5} \mathrm{~mm} / \mathrm{mm} /{ }^{\circ} \mathrm{C}\left(8.82 \times 10^{-5}\right.$ \\
\hline Tensile Modulus & $2,200 \mathrm{MPa}(320,000 \mathrm{psi})$ \\
\hline
\end{tabular}

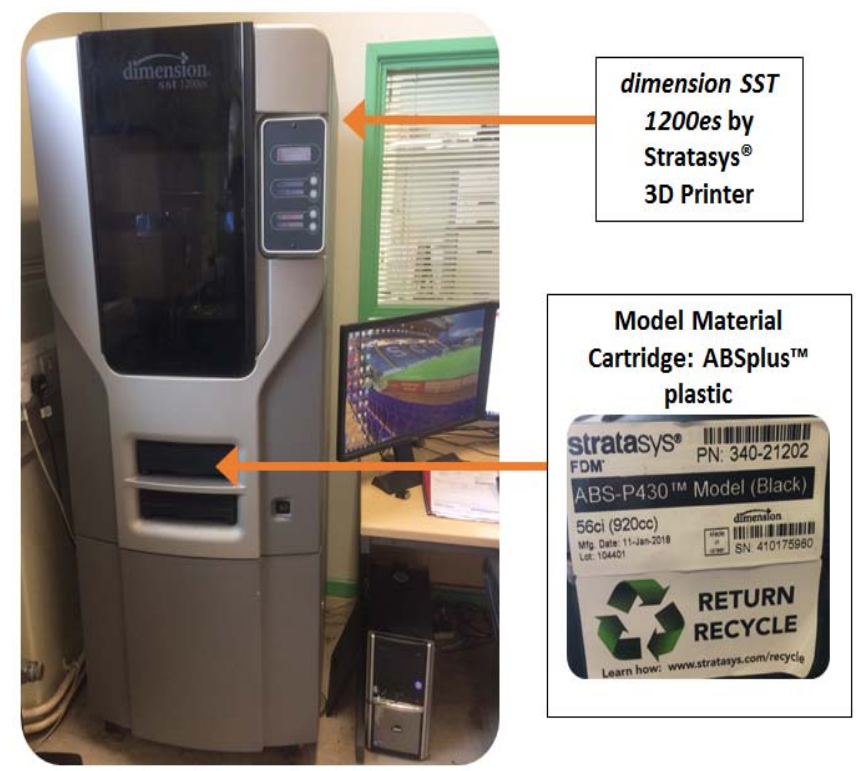

Fig. 7: Commercial 3D RP machine at the University of Manchester

After individual non-magnetised segments were laid on the base arc and their joint side surfaces coated with adhesive, the base cover and compression screws were applied to provide retention of the PM material volume in the desired geometry until the adhesive has fully bonded. Once the PM arc segments have been completed, the arc assembly rigs were used to enable PM location and protection during the magnetisation process. For this purpose, the assembly rigs containing finalised PM arc sections were appropriately positioned inside the magnetiser chamber of a commercial magnetiser machine, before performing full magnetisation at $\approx 3000 \mathrm{~V} / 12.0 \mathrm{kA}$ settings. The rigs were found to enable straightforward positioning, retention and protection of the PM volume during the magnetisation process. Finally, the magnetised PM segments were checked using a commercial Fluxmeter. Fig. 10 shows the magnetiser schematic test rig diagram and the use of the PM arc assembly rig for the magnetisation process. 


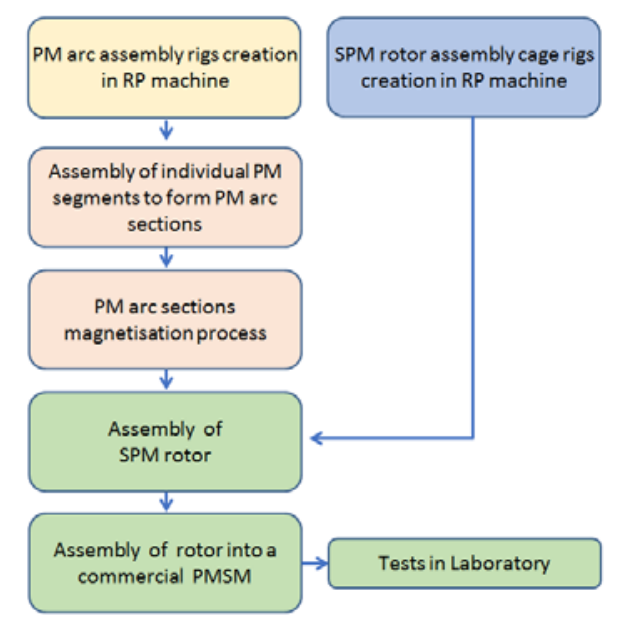

Fig. 8: SPM prototype proposed assembly process flow diagram

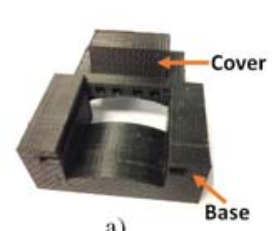

a)

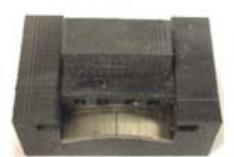

d)

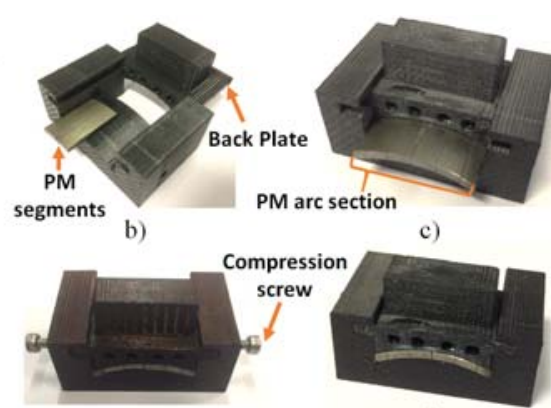

f)
Fig. 9: PM arc assembly rig: a) cover and base, b) PM segment insertion, c) PM arc section formation, d) PM arc section volume retention e) compression screws to constrain the segmented arc assembly, f) final PM arc

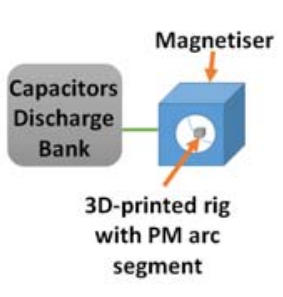

a)

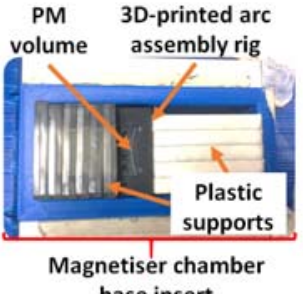

b)
Fig. 10: PM arc section magnetizing process: a) magnetiser test rig schematic diagram b) PM arc section positioning

The assembly process of completed pre-magnetised PM arcs into an SPM rotor was undertaken using the proposed rotor assembly cage design as illustrated in the flow chart in Fig. 8. Fig. 11a shows the front and back cover rapid prototypes developed in section $\mathrm{V}$ for this purpose. The covers were designed to comprise of two interlocking halves in order to enable easy in-situ assembly at the two extremes of the rotor shaft. Once the covers and spacers are assembled on the rotor, axial tensioning screws are inserted to facilitate alignment and correct location of individual PM pole sections, and ensure these are kept in place during the assembly process. The complete PM rotor assembly cage rig is shown in Fig. 10.b. With the cage installed on the rotor, adhesive (LoctiteC 648) was applied on the exposed core surface pole area and individual PM arc sections then inserted and guided to their correct position by using the cage spacers: this process was repeated until the entire PM pole was completed.

When all the poles were assembled, the front and back cage covers were compressed to the rotor core with the aid of the screws to align the ends of PM poles and keep them in position until the applied adhesive dries and cures. The final process to complete the SPM rotor prototype was to band the rotor with commercial glass-reinforced fibre yarn and a PF $100^{\circ}$ polyester resin to cure it. Fig. 12 shows the details of the assembly process.

To enable practical build of a desired partially demagnetised PM rotor and its arc topology, segment inserts corresponding to PM arc individual sections' geometry were $3 \mathrm{D}$ printed and used in the build and magnetisation process. This is illustrated in Fig. 13 for an example of individual PM arc build where $50 \%$ of total segments are demagnetized from the arc edge to its centre. Following the methodology described in previous paragraphs the $50 \%$ demagnetized arc is produced by first building two separate half arcs, then magnetizing one of them in the assembly rig in situ while utilizing the 3D printed segment inserts to ensure positioning, retention and protection of the PM volume during the magnetisation process, and finally bonding the magnetised and demagnetised sections to form a full pole arc. Individual arcs are then assembled into a complete rotor architecture following the process illustrated in Fig. 12.

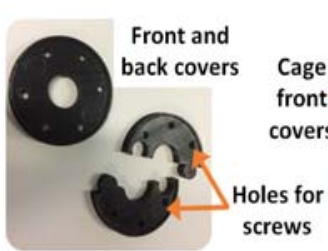

a)

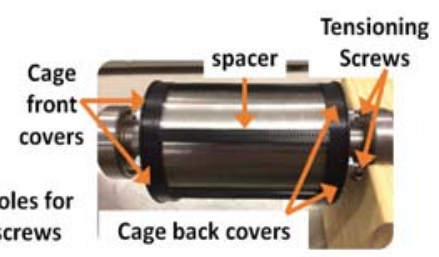

b)
Fig. 11: PM rotor assembly cage rapid prototype: a) front and back cover, b) complete cage assembly mounted on the rotor

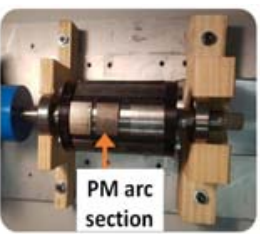

a)

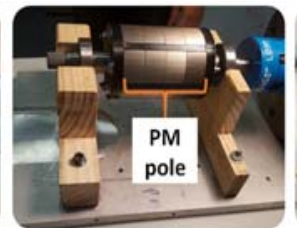

b)

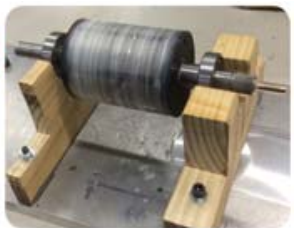

c)
Fig. 12: SPM prototype assembly process: a) PM arc sections positioning, b) complete PM poles assembly, c) final SPM rotor

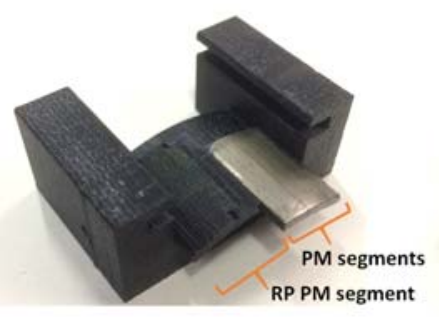

a)

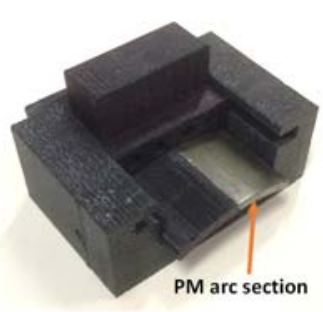

b)
Fig. 13: Partially demagnetised PM sections assembly: a) PM segments insertion, b) final half $\mathrm{PM}$ arc 


\section{Final Prototype Results}

Two SPM rotors were built for the purpose of this research to verify the ability of using RP assemblies on a commercial SPM design for segmented PM arc rebuild and PM demagnetisation fault emulation; the examined topologies are identical to those discussed in section VI.B. For the healthy rotor, the arc segments of all the PM poles were magnetised uniformly, while $50 \%$ of PM arc sections on all poles were assembled in a demagnetised state for the faulted rotor: the non-banded rotor prototypes are shown in Fig. 14.

The performance of built PM rotors was examined in experiments on a laboratory test-rig whose configuration is shown in Fig. 15; the commercial SPM equipped with the modified rotors was mechanically coupled to a DC motor prime mover. The rig is designed to enable rotation of PM rotor prototypes at desired speed and measurement of the corresponding back electro-motive force (BEMF) signals in the open circuited stator windings. The SPM phase voltage signals were monitored by LeCroy ADP300 voltage probes connected to a LeCroy 434 digital oscilloscope sampling at 5 $\mathrm{kHz}$ to record the data during the tests.

To evaluate the performance of the two built rotors, experimental tests were performed at nominal speed, 1800 $\mathrm{rpm}$, and half speed, $900 \mathrm{rpm}$, to measure the BEMF signals. Figs. 16 and 17 show the comparison of the measured signals for healthy and faulty rotors. The measured BEMF in phase $\mathrm{U}$ at nominal speed corresponds to $\approx 153 \mathrm{~V}$ rms for a healthy $\mathrm{PM}$ rotor, whereas for the faulty rotor is $\approx 77 \mathrm{~V}$ rms. This reduction is expected to occur due the reduction of the number of magnetised PM segments: a similar level reduction between fully and partially magnetized rotors' $\mathrm{BEMF}$ is seen at half speed operation.

The measurements in Figs. 17 and 18 clearly show the effect of PM arc demagnetisation in emulated faulty conditions, resulting in a change in air-gap magnetic flux density distribution and consequently in the observed BEMF shape modulation. This is further illustrated in the measured healthy and faulty BEMF spectra comparison at nominal speed in Fig. 18: the air-gap flux density distribution symmetry modification induced by a uniform $50 \%$ reduction of active PM arc length on all poles is clearly seen to modulate the $3^{\text {rd }}, 5^{\text {th }}$ and particularly the $7^{\text {th }}$ harmonic in the spectrum, in addition to the reduction of the fundamental.

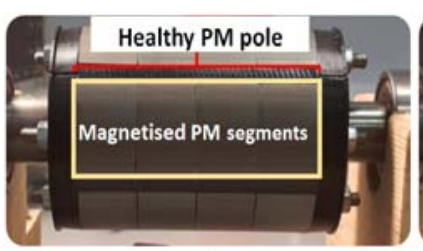

a)

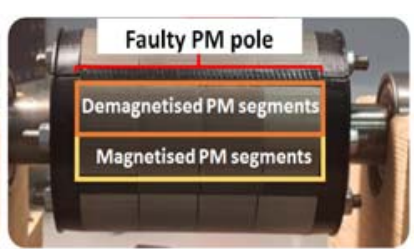

b)
Fig. 14: Experimental rotor prototypes: a) healthy rotor b) faulty rotor

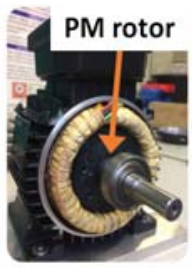

a)

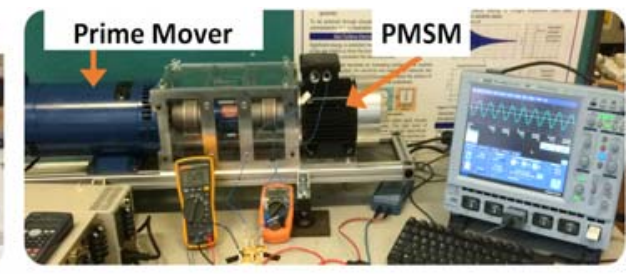

b)
Fig. 15: Experimental test rig: a) commercial SPM with modified rotor b) test rig set-up

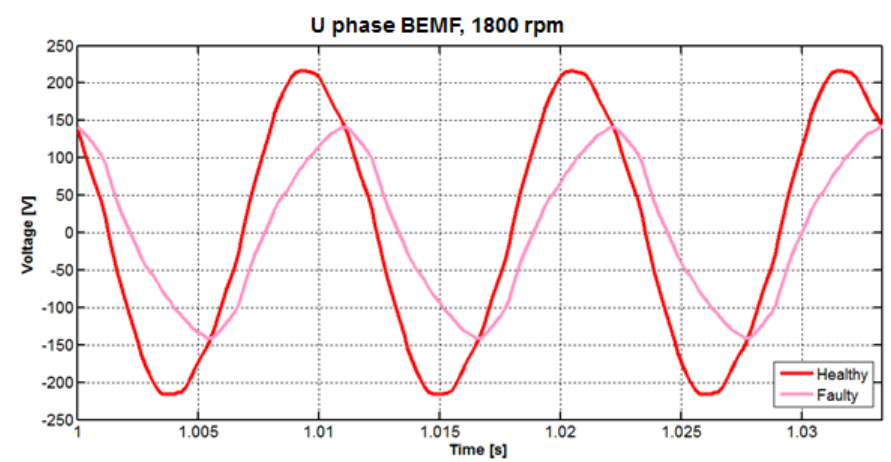

Fig. 16: Comparison of measured BEMF for a healthy and faulty SPM at $1800 \mathrm{rpm}$

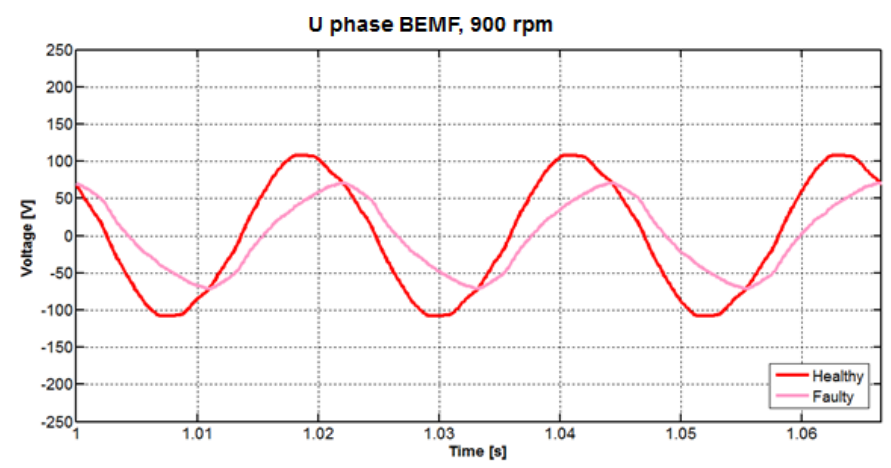

Fig. 17: Comparison of measured BEMF for a healthy and faulty SPM at $900 \mathrm{rpm}$

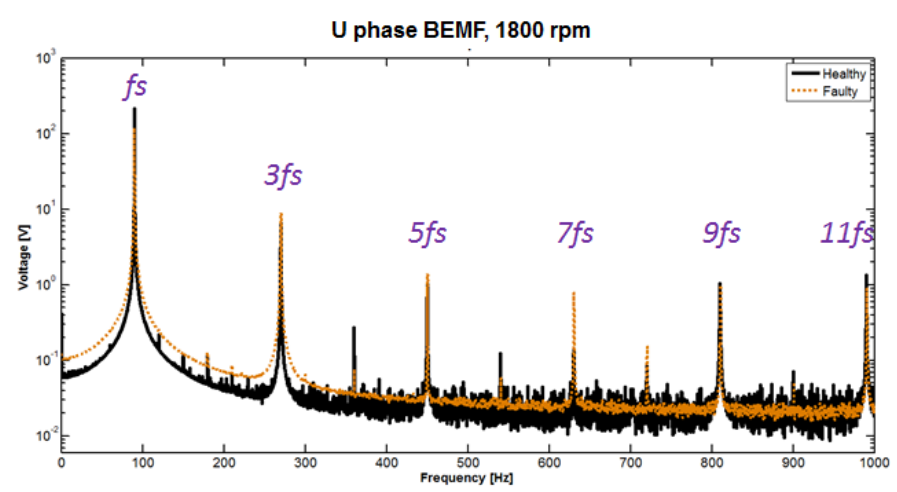

Fig. 18: Harmonic spectrum of phase U BEMF comparison of for a healthy and faulty SPM at $1800 \mathrm{rpm}$ 


\section{CONCLUSIONS}

This paper examines the feasibility of non-conductive 3D rapid prototype rigs use for controlled PM arc build and magnetisation and SPM rotor assembly. The results show that the rapid prototype rigs can present an effective means in this role and provide an attractive alternative to conventional fixture construction techniques (e.g. CNC machining) in terms of production time demand and ease and cost of application.

The design, build and application procedures of the proposed assembly rig geometries are reported and these applied on a particular PMSM topology examined in this study. The proposed methodology was validated in experiments by undertaking the build of two SPM rotors, one fully magnetised and the other with a $50 \%$ reduction in magnetised PM material. Illustrative results of machine operation at nominal and half speed for fully and partially magnetised rotors show that application of 3D printing technology can innovate the construction of SPM prototypes for laboratory experimentation purposes, which is particularly attractive in academic research environments: the proposed 3D-printed rig architectures can provide an effective and low cost method that allows relatively straightforward build of desired SPM rotor PM design. The presented principles can be extrapolated to arbitrary SPM rotor designs following the reported methodology.

\section{REFERENCES}

[1] B. Sarlioglu, C. T. Morris, D. Han and S. Li, "Driving Toward Accessibility: A Review of Technological Improvements for Electric Machines, Power Electronics, and Batteries for Electric and Hybrid Vehicles," in IEEE Industry Applications Magazine, vol. 23, no. 1, pp. 14-25, Feb. 2017.

[2] Automotive Council UK. Advanced Propulsion Centre UK www.apcuk.co.uk/app/uploads/2018/02/EMC_Full_Pack.pdf

[3] M. J. Melfi, C. Wright, R. Hts, S. Evon, and R. Mcelveen, "Permanent Magnet Motors for Power Density and Energy Savings in Industrial Applications," in Pulp and Paper Industry Technical Conference, 2008. PPIC 2008. Conference Record of 2008 54th Annual, 2008.

[4] S. Choi et al., "Fault Diagnosis Techniques for Permanent Magnet AC Machine and Drives-A Review of Current State of the Art," in IEEE Transactions on Transportation Electrification, vol. 4, no. 2, pp. 444463, June 2018.

[5] E. Joseph, J. Tremel, B. Hofmann, A. Meyer, J. Franke and S. Eschrich, "Automated magnet assembly for large PM synchronous machines with integrated permanent magnets," 2013 3rd International Electric Drives Production Conference (EDPC), Nuremberg, 2013, pp. 1-6.

[6] Arnold Magnetic Technologies, "Preciision magnetic assemblies", 2018. www.arnoldmagnetics.com

[7] Integrated Magnetics. "Magnetics 101 - Design Guide", 2018. www.intemag.com

[8] W. le Roux et al, "Detecting rotor faults in low power permanent magnet synchronous machines," IEEE Trans. Power Electron., vol. 22/1, pp. 322-8, 2007.

[9] J. Urresty, R.J. Riba, L. Romeral, "Back-emf based method to detect magnet failures in PMSMs magnetics”, IEEE Trans. Magn. 49 591598. 2013.

[10] Juan I. Melecio, S. Djurovic, N. Schofield, “An FEA model study of spectral signature patterns of PM demagnetization faults in synchronous PM machines", 9th IET International Conference on Power Electronics Machines and Drives (PEMD 2018), April, 2018.

[11] C.S.A. Casadei Domenico, Filippeti Fiorenzo, Rossi, "Magnets Faults Characterization for Permanent Magnet Synchronous Motors," IEEE
International Symposium on Diagnostics for Electric Machines, Power Electronics and Drives, 2009

[12] J. A. Rosero, J. Cusido, A. Garcia, J. A. Ortega, and L. Romeral, "Study on the Permanent Magnet Demagnetization Fault in Permanent Magnet Synchronous Machines," IECON 32nd Annual Conference on IEEE Industrial Electronics, 2006, pp. 879-884.

[13] M. Zafarani, S. Member, T. Goktas, S. Member, B. Akin, and S. Member, "A Comprehensive Analysis of Magnet Defect Faults in Permanent Magnet Synchronous Motors," in Applied Power Electronics Conference and Exposition (APEC), 2015, vol. 52, no. 2, pp. 3-7.

[14] Chua, C.K., Leong, K.F., "Rapid Prototyping: Principles and Applications", Second Edition. World Scientific Publishing Co, Singapore, 2003.

[15] Flaviana. Calignano et al., "Overview on Additive Manufacturing Technologies," Proceedings of the IEEE, vol. 105, no. 4, pp. 593-612, April 2017.

[16] Berman, Barry, “ 3-D printing:The new industrial revolution”. Business Horizons . Vol.55, Issue 2, pp 155-162. 2012.

[17] Huang, S.H., Liu, P., Mokasdar, A. et al."Additive manufacturing and its societal impact: a literature review" Int. Journal of Advanced Manufacturing Technology pp.67: 1191, 2013.

[18] H. Hong, H. Liu, S. Cho, J. Lee and C. Jin, "Design of High-End Synchronous Reluctance Motor Using 3-D Printing Technology", IEEE Transactions on Magnetics, vol. 53, no. 6, pp. 15, June 2017.

[19] Michele Garibaldi, Chris Gerada, Ian Ashcroft, Richard Hague, Herve Morvan, "The Impact of Additive Manufacturing on the Development of Electrical Machines for MEA Applications: A Feasibility Study", MEA2015 More Electric Aircraft, Feb 2015, Toulouse, France.

[20] Berman, B., "3-D printing: The new industrial revolution", Business Horizons, vol. 55, no.2, pp. 155-162, 2012.

[21] Attaran, Mohsen, "The rise of 3-D printing: The advantages of additive manufacturing over traditional manufacturing”, Business Horizons, vol.60, no.5, 2017.

[22] Gardan, Julien, "Additive Manufacturing Technologies: State of the Art and Trends". International Journal of Production Research, Nov 2017.

[23] Muita, K., Westerlund, M., Rajala., R. "The Evolution of Rapid Production: How to Adopt Novel Manufacturing Technology", IFACPapersOnLine 2015, vol.48, pp.32-37.

[24] F. Lorenz, J. Rudolph and R. Werner, "High Temperature Operation and Increased Cooling Capabilities of Switched Reluctance Machines using 3D Printed Ceramic Insulated Coils," 2018 IEEE Transportation Electrification Conference and Expo (ITEC), Long Beach, CA, 2018, pp. 400-405.

[25] Stratasys. "Dimension 1200es 3D Printer", 2019. www.stratasys.com 